\title{
Our Positive and Negative Deductions regarding the Results of Tumor Prostheses after Resection of Primary and Metastatic Tumors of the Proximal Humerus
}

\author{
(1) Ertuğrul Allahverdi, ${ }^{1}$ (1) Yusuf Yıldız \\ 'Department of Orthopedics and Traumatology, Kafkas University Faculty of Medicine, Kars, Turkey \\ ${ }^{2}$ Department of Orthopedics and Traumatology, Ankara University Faculty of Medicine, Ankara, Turkey
}

\section{ABSTRACT}

Objectives: The aim of modular tumor prostheses for primary and metastatic tumors of the proximal humerus is to provide the maximum possible physical, psychological and social activity despite the wide resection areas. The present study aims to show the suitability of modular tumor prostheses of the shoulder joint in the early period without considering the postoperative life expectancy in patients diagnosed with a malignant tumor of the proximal humerus.

Methods: In this study, a total of 53 patients were evaluated retrospectively. Our patients consisted of $32 \mathrm{fe}-$ male and 21 male patients who were diagnosed and underwent surgery at our Orthopedics and Traumatology clinics between 1980 and 2003. The 14 patients we had personally followed-up at our clinic were included in Group A, while the 39 patients who were evaluated using the data in the archives were included in Group B. The mean age of the patients was 57 years in Group $A$ and 39 years in group B. Modular tumor prostheses were mostly used for the 53 patients in total in Group A and B, but a few patients received a tumor prosthesis made of Polyacetalharz or an isoelastic tumor prosthesis.

as: Alte this artic Our Positive and Negative Deductions regarding the Results of Tumor Prostheses after Resection of Primary and Metastatic Tumors of the Proximal Humerus. Anatol J Family Med 2019;2(3):119-125.

Address for correspondence: Dr. Ertuğrul Allahverdi.

Department of Orthopedics and Traumatology, Kafkas University Faculty of Medicine, Kars, Turkey

Phone: +90 5064280784

E-mail:

ertugrulallahverdi@hotmail.com

Received Date: 30.05.2019

Accepted Date: 19.06.2019

Published online: 14.11.2019

@Copyright 2019 by Anatolian Journal of Family Medicine -

Available online at www.anatoljfm.org

OPEN ACCESS

Results: There was no sign of postoperative metastasis or local residual tumor in any of the 14 patients in Group A. Seven patients had no pain and five patients had only mild pain. None of the patients required opioids. Postoperative cranial subluxation was seen in ten patients after a mean duration of 34.5 months. Resurgery was performed only in four of 14 patients in group A. Multiple bones, or visceral/pulmonary metastases were found at the same time as the initial diagnosis in Group B patients, and these subjects died within a mean postoperative duration of six months. Nine of the 39 patients underwent resurgery. There were six patients with no pain in Group B. There was no recorded data related to pain in 25 patients. The movement limitation was significant in 13 patients and mild in two patients.

Conclusion: The findings suggest that it was possible to achieve a good level of movement capacity and muscle strength although limited due to the refixation of the muscles and tendons protected during the wide intraoperative resections with modular tumor resection prosthesis implantation, despite some tolerable pain in the early period, when the results were compared with other treatment options, such as arthrodesis or amputation. It is encouraging that the elbow, forearm and hand functions were fully protected in all patients and good quality of life was ensured considering the cosmetic results, patient psychology and daily social activities.

Keywords: Humerus,bone neoplasms, shoulder prosthesis, joint prosthesis

\section{INTRODUCTION}

Modular tumor prosthesis use can ensure optimal treatment continuity, protect the extremity and improve shoulder movement after tumor resection surgery following the diagnosis of primary and metastatic tumors of the proximal humerus. Modular tumor prosthesis is also an 
important and positive step regarding the patients maintaining their shoulder, elbow, and wrist functions as well as their social activities and aids the attempts to improve their physical, psychological and social activities with the proper postoperative physical therapy and psychotherapy.

This study aims to evaluate the potential use of modular tumor prostheses suitable for the shoulder joint in the early period without considering the postoperative life expectancy in patients diagnosed with a malignant tumor of the proximal humerus. Other aims were to show that shoulder prosthesis as used in our clinic could ensure anatomical reconstruction and increase the psychosocial quality of life of tumor patients, and to review the relevant experience and research on tumor prosthesis procedures in orthopedics and tumor surgery using data from the global literature. Extremity-protecting reconstruction methods include bone transplantations, for example, allograft or autograft, arthrodesis and tumor prosthesis implantation. ${ }^{[1-3]}$ The shoulder anatomy should be considered in all reconstruction procedures since a reconstructive procedure and tumor prosthesis implantation conducted close to the shoulder should be able to provide an acceptable function for the patient. ${ }^{[4]}$ The main limit of the operative treatment is its planning as an extremity-protecting reconstruction surgery to provide maximum functionality of the muscular, tendon and neurovascular structures. As in other skeletal parts, the movement capacity of the shoulder joint can be improved with specifically designed modular and reverse type tumor prosthesis use in the shoulder region. ${ }^{[1,5-7]}$ Modular tumor prostheses have now been modernized and become more useful with joint components. The modularity of these prostheses, in contrast to monoblock prostheses, allows the changing arm length to conform once again to the normal anatomical structure thanks to the different resection limits. ${ }^{[5,6]}$

\section{METHOD}

A total of 53 patients were evaluated retrospectively in this study. The subjects consisted of our patients who had undergone shoulder tumor prosthesis implantation due to primary or metastatic tumor of the proximal humerus after diagnosis at the Department of Orthopedics at Ankara University Ankara Faculty of Medicine between 1980 and 2003 and who had pre-, intra- and postoperative samples. The 53 patients consisted of 14 patients who were seen at our clinic and included in Group A and 39 patients who were evaluated according to their documents and data in the archive files and included in Group B. No comparison was made between the groups. Movement capacity measurements were performed to determine postoperative shoulder joint functions using the Musculoskeletal Tumor Society (MSTS) Scores and the Neutral-Zero Method were obtained from the archive records. Our measurements were performed according to the Constant-Murley shoulder evaluation in Group A. Evaluation of shoulder function and muscle strength was with specific shoulder function tests. Strength determination was made directly according to the data of the side with pathology and that of the healthy side. The movement capacity of the shoulder was measured with a goniometer. The movement functions and shoulder functionality was evaluated both with subjective and objective parameters using Constant and Murley scoring. ${ }^{[8]}$ MSTS scoring was developed to determine the movement functions after the implantation of extremity-protecting prostheses, amputations and reconstructive surgery. ${ }^{[9]}$ The values for pain, function, psychological acceptability and many other specific factors (active movement, fine motor/sensitivity and strength) were recorded for the upper extremities during this scoring. ${ }^{[1,11-14]}$

\section{RESULTS}

Follow-up examinations continued in 11 (78.6\%) of 14 patients while one of our patients did not receive postoperative treatment and two patients completed postoperative follow-ups. No metastasis was found in Group A patients. Postoperative follow-up examinations were conducted in $14(26.4 \%)$ patients eight (57.1\%) female and six (42.9\%) male patients). The mean age was $57.9 \pm 1.7$ years. Eight (57.1\%) patients were diagnosed as primary malignant tumors: two (14.3\%) of them had parossal osteosarcoma; three (21.4\%) patients had chondrosarcoma; one $(7.1 \%)$ of them was parossal chondrosarcoma), one (7.1\%) patient had Ewing's sarcoma; one (7.1\%) patient had malignant fibrous histiocytoma of the bone and one (7.1\%) had Plasmacytoma. A benign bone tumor was found in three (21.4\%) patients, consisting of proliferated chondromas in one patient and stage 3 osteoclastoma (=Giant cell tumor) in two (14.3\%) was found patients. NonHodgkin's lymphoma in one (7.1\%) patient and metastatic hypernephroma carcinoma in two (14.3\%) patients. The resection was large in five (35.7\%) patients, large/contaminated in two patients, marginal in four (28.6\%) patients, marginal/contaminated in one patient and intralesional in two (14.3\%) patients. The MUTARS Prosthesis (Modular Universal Tumor and Revision System, Implantcast, Buxtehude, Germany) was used in 14 (26.4\%) patients, a modular tumor prosthesis (TMTS= Turkish Musculoskeletal Tumor Society, Hippocrates) in one (7.1\%) patient and a tumor prosthesis made of Polyacetalharz in one $(7.1 \%)$ patient in group A. The shoulder on the prosthesis arm had a mean passive abduction of $83.0 \pm 1.6^{\circ}$ (the mean value for the healthy shoulder was 
$\left.180^{\circ}\right)$, anteversion of $95^{\circ}\left(180^{\circ}\right)$, retroversion of $65^{\circ}\left(35^{\circ}\right)$, internal rotation of $95.0 \pm 1.8^{\circ}\left(100^{\circ}\right)$, external rotation of $93.1 \pm 1.8^{\circ}\left(70^{\circ}\right)$ and adduction of $23.4 \pm 1.6^{\circ}\left(35^{\circ}\right)$. The best passive moment ratio of the shoulder prosthesis arm was in anteversion, followed by an external rotation, internal rotation and adduction. Retroversion was less successful and abduction was the worst $(p<0.001)$. The mean values of retroversion and external rotation in passive movement in the relevant arm for Group A patients were found to be better than the mean movement values in the contralateral healthy shoulder $(p=0.007)$. The refixation of the rotator cuff muscles directly to the prosthesis or to the polyester (Dacron) mesh, which is the connection sheath, to conform to the anatomic structure, was not fully possible. Besides, postoperative muscle weakness was seen in the arm with the shoulder prosthesis $(p=0.01)$. It was not possible to relieve the muscle tension completely $(p=0.003)$. However, the movement capacity in the operated shoulder joint increased significantly despite the intra and postoperative soft-tissue deficiencies and even supranor-mal movement could be observed $(p<0.001)$.

Resurgery was required only in four (28.6\%) of the 14 patients in Group A. Partial humerus prosthesis change was performed in two (14.3\%) of these patients. Total humerus prosthesis change was required in the one patient $(7.1 \%)$ due to the loosening of the prosthesis. The one patient (7.1\%) patient required complete removal due to prosthesis fracture and accompanying soft tissue infection, together with the risk of soft tissue perforation following cranial mobilization of the prosthesis. Local infection treatment was started with septopalket and a tumor prosthesis implantation was not performed in this patient after follow-up. There was also neurological damage in two (14.28\%) patients in Group A. The neural tissues were either quite near the malignant tumor mass or extended inside the tumor. $\mathrm{N}$. axillaris resection was required in only one patient and $\mathrm{N}$. radialis, $\mathrm{N}$. ulnaris and $\mathrm{N}$. medianus resection in one patient $(7.1 \%)$. There was no sign of metastasis or local residual tumor in any of the 14 patients in Group A. No pain was present in seven $(50.0 \%)$ patients, while five (35.7\%) patients complained of mild pain. None of the patients required opioids. Cranial subluxation was seen in ten patients after a mean postoperative duration of $34.5 \pm 1.2$ months. Evaluation of the adaptation of the modular tumor prosthe-sis to the glenoid in Group A patients where a mesh graft (nonabsorbable) had been used $(n=8)$ revealed cranial subluxation in five (12.8\%) patients and lateralization of the prosthesis head from the glenoid in one (2.6\%) patient. There was no problem with the prosthesis implantation of two (5.1\%) patients (Figs. 1-4). When the adaptation of the prosthesis was evaluated according to the

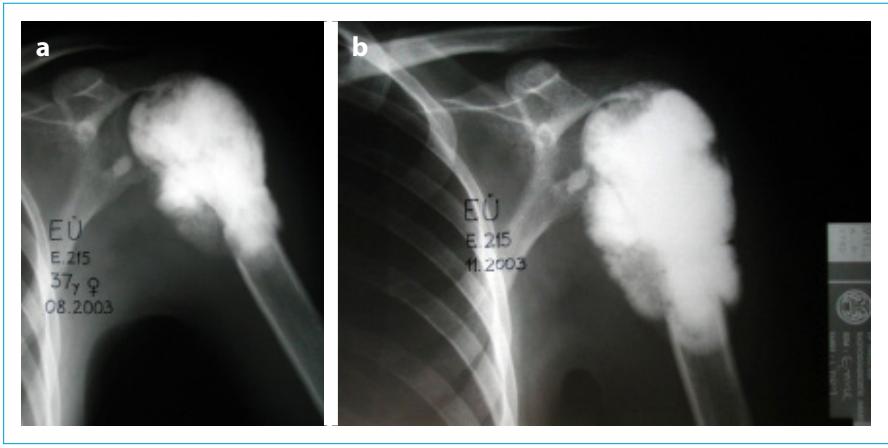

Figure $1(\mathbf{a}, \mathbf{b})$. X-ray radiographs of the preoperative left humerus showed osteosarcoma and soft tissue invasion in the proximal humerus.

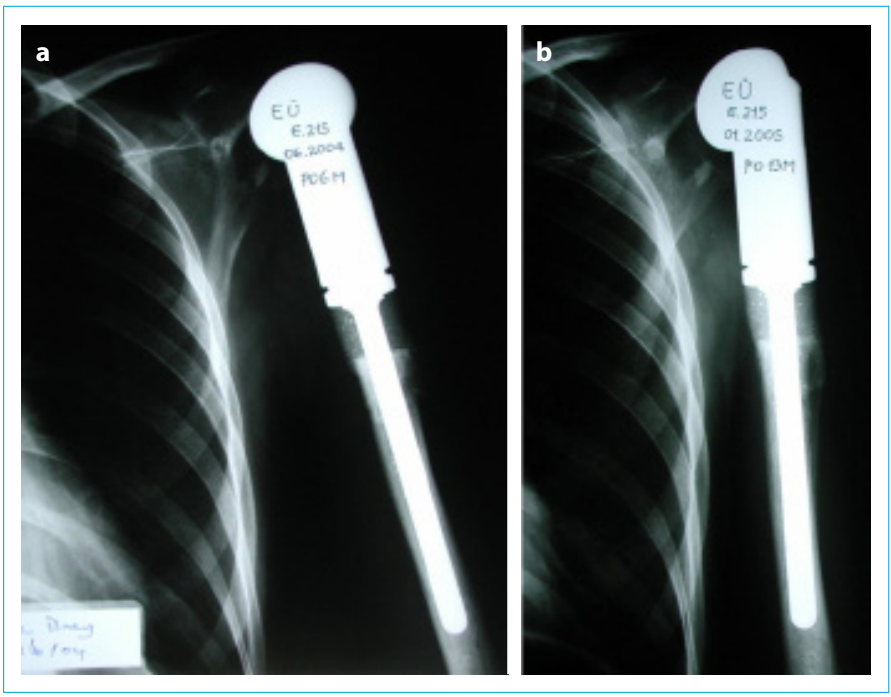

Figure $2(\mathbf{a}, \mathbf{b})$. Postoperative $6^{\text {th }}$ and $12^{\text {th }}$-month posteroanterior left humerus X-ray follow-up graphs showed the Hippocrates TMTS prosthesis location and cranial subluxation. No signs of loosening of the prosthesis are observed.

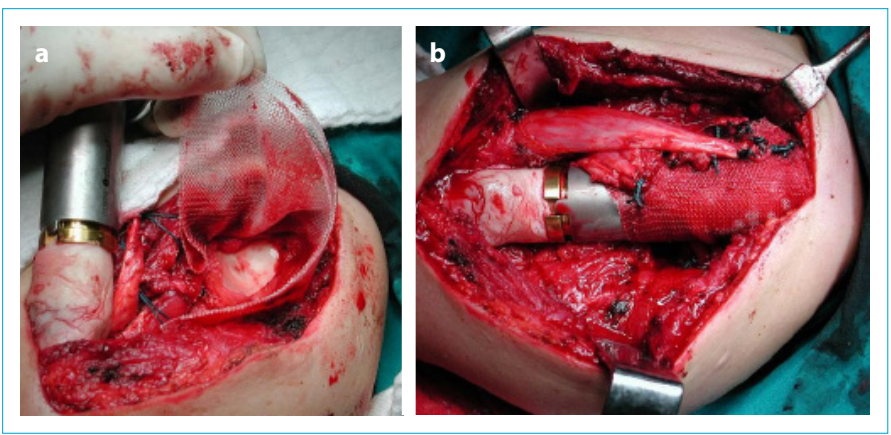

Figure $\mathbf{3}(\mathbf{a}, \mathbf{b})$. Implantation of the intraoperative Hypocrite TMTS shoulder prosthesis to the humerus and the status after suturing the polyester (Dacron) mesh to the capsule.

glenoid in patients who did not receive a Polyester Mesh Graft (Dacron) $(n=4)$, cranial subluxation was seen in three (7.7\%) patients while the implanted prosthesis was normal in one patient. Subluxation was observed in both of 


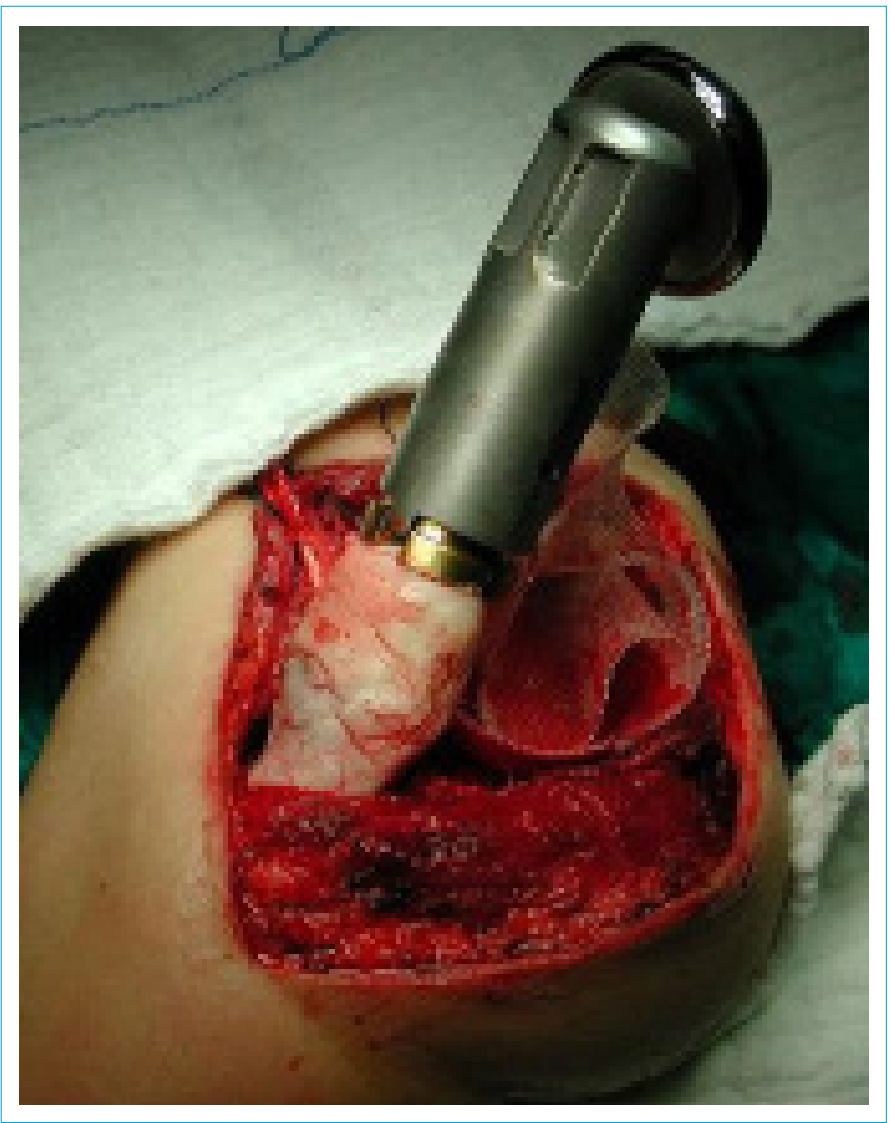

Figure 4. The placement of the intraoperative implanted TMTS prosthesis in the glenoid and stitching of the polyester (Dacron) mesh. This was followed by the fixation of the rotator cuff to the remaining muscles and tendons and the stitching of the long head of the biceps tendon to the mesh from the anterior part.

the patients $(n=2)$, where a sheath had been formed with autologous fascia lata. The mean MSTS score was $63.7 \pm 1.3$ in Group A, while the highest scores were for fine motor/ sensory (mean 5 points $5.0 \pm 1.1$ ), the lowest scores were for movement functions (mean 2 points $2.1 \pm 1.0$ ). The mean value recorded was $3.6 \pm 1.1$ for pain, $2.8 \pm 1.2$ points for strength and $2.1 \pm 1.4$ points for active movement capacity. None of the patients could abduct their arm $90^{\circ}$ postoperatively, and the maximum abduction amount was $60^{\circ}$. The maximum active anteversion recorded was $70^{\circ}$.

The existing file data of 39 patients in group $B$ were used for the shoulder functions. A part of this group was not alive or not able to attend follow-ups. The data of 13 (33.3\%) patients from this group attending the follow-ups were obtained from the file records. X-rays were also obtained during follow-up in these patients. Group B consisted of 15 (38.5\%) male and 24 (61.5\%) female patients in total. The mean age of the patients in Group B was 39.7 \pm 5.1 years. The mean age at death was $60.1 \pm 1.6$ years. The pri-mary and metastatic tumor distribution of the patients in Group $B$ is presented in Table 1. The tumor resection limits in group B patients were as follows: ten patients (25.6\%) underwent intralesional, twenty (51.3\%) patients margin-al and nine (23.1\%) patients wide resection. The shoulder prosthesis types used were the MUTARS prosthesis, Modular Tumor Prosthesis (TMTS), Isoelastic Tumor Prosthesis and Polyacetalharz prosthesis. Multiple bone or multiple visceral/pulmonary metastases were found at the time of the initial diagnosis and most of them died within a mean duration of 6 months $6.1 \pm 1.2$. Nine (23.1\%) of the 39 patients underwent resurgery. The reason was postoperative bleeding in two (5.1\%) patient, local metastasis in one (2.6\%) patient, prosthesis luxation along with local metastasis in one (2.6\%) patient, prosthetic loosening in one $(2.6 \%)$ patient, presence of residual tumor in one (2.6\%) patient, prosthesis fracture in one $(2.6 \%)$ patient and detection of infection in two (5.1\%) patients. N. radialis paresis was seen in three $(7.7 \%)$, residual tumor in five $(12.8 \%)$, prosthetic loosening in one (2.6\%) patient and cranial migration as determined according to the glenoid cavity in three (7.7\%). Mild pain was

Table 1. The Primary Tumors/Metastases of the 39 Patients in Group B

\begin{tabular}{|c|c|c|c|}
\hline Primary Tumor & n=Patients $(\%)$ & Metastasis & n=Patients $(\%)$ \\
\hline Hemangioma & $1(2.6)$ & Breast Carcinoma & $4(10.3)$ \\
\hline B-cell lymphoma in the Bone & $1(2.6)$ & Hypernephroid Carcinoma & $9(23.1)$ \\
\hline Osteoclastoma, Aggressive & $1(2.6)$ & Larynx Carcinoma & $1(2.6)$ \\
\hline Plasmacytoma & $3(7.9)$ & Prostate Carcinoma & $2(5.1)$ \\
\hline Chondrosarcoma & $1(2.6)$ & Colon Carcinoma & $1(2.6)$ \\
\hline Ewing's Sarcoma & $1(2.6)$ & Follicular Thyroid Gland Carcinoma & $1(2.6)$ \\
\hline Histiocytoma & $1(2.6)$ & Rectum Carcinoma & $2(5.1)$ \\
\hline Fibrosarcoma, Aggressive & $1(2.6)$ & Hepatocellular Carcinoma & $1(2.6)$ \\
\hline \multirow[t]{2}{*}{ Osteosarcoma } & $2(5.1)$ & Uterine Carcinoma & $1(2.6)$ \\
\hline & & Unidentified Primary Tumors & $5(12.8)$ \\
\hline Total & & & $39(100.0)$ \\
\hline
\end{tabular}


present in four (10.3\%), strong pain in two (5.1\%) patients, pain due to pressure in one $(2.6 \%)$ patient and pain due to movement in one $(2.6 \%)$ patient. There were six (15.4\%)s with no pain. There was no record of pain in 25 (64.1\%) patients, a marked limitation of movement in 13 (33.3\%) patients, and mild limitation of movement in two (5.1\%) patients while there was no data on the shoulder movement capacity in 24 patients. Radiological cranial subluxation was seen in two (5.1\%) patients and the prosthesis was cranially located but not subluxated in one (2.6\%) patient. No subluxation was seen in ten (25.6\%) patients. Postoperative prosthesis implantation radiological data of 26 (66.7\%) patients could not be found in the archive records.

\section{DISCUSSION}

Primary malignant tumors of the proximal humerus are the third most common malignant tumors in the body. Malignant tumor metastases are also mostly localized to the proximal humerus. ${ }^{[3-5,8,10,14,15]}$ The aim of treatment in modular tumor resection shoulder prostheses used after malignant tumors is to ensure the maintenance of the shoulder and arm anatomy, ${ }^{[7,15-18]}$ to ensure function, and to maintain the function of the elbow, hand and finger joints. ${ }^{[5,6,10,15,16,19]}$ Tumor prostheses have a joint component, with primarily a central part and an intramedullary shaft part. The MUTARS prosthesis and TMTS can be provided as examples. ${ }^{[6]}$ The implantation of shoulder prostheses that protect the extremity and maintain joint movements has been satisfactory both for the patient and the physician thanks to the advances in surgical-reconstructive approaches to the proximal humerus tumors in the last 30 years. However, there is generally a limitation in the shoulder movements after surgical interventions for tumors in the shoulder region. Many limitations in daily life have been reported with loss of strength. Consequently, the inability to lift the arm at the shoulder level on the pathological side in many patients. ${ }^{[5,11,14,19-22]}$ The mean active movement degrees of the patients in Group A were $27.5^{\circ}\left(0-60^{\circ}\right)$ for abduction; $20^{\circ}$ $\left(0-70^{\circ}\right)$ for anteversion; $75^{\circ}\left(0-90^{\circ}\right)$ for internal and external rotation; $30^{\circ}\left(20-70^{\circ}\right)$ for retroversion and $10^{\circ}\left(0-40^{\circ}\right)$ for adduction in this study. The active movement degrees of the shoulder were $25-45^{\circ}$ for abduction; $30-55^{\circ}$ for anteversion; $15-90^{\circ}$ for internal rotation; $15-80^{\circ}$ for external rotation; $20-30^{\circ}$ for retroversion and $10-30^{\circ}$ for adduction in comparative studies..$^{[5,7]}$ Regular physiotherapy has been used to strengthen healthy muscular tissues after surgical intervention. However, the prosthesis showed cranial subluxation in many cases. This complication was also frequently observed in the other similar studies. . $^{[3,4,7,10,11,13-15,18,23]}$ Cranial subluxation of the prosthesis occurred nine months after surgery in another study. ${ }^{[1]}$ Shoulder subluxations were observed with the prostheses after a mean postoperative duration of 34.4 months in our study. Although it was thought that the proper intraoperative refixation of the muscles to the tumor prosthesis using a Polyester Mesh graft would prevent the subluxations ${ }^{[7,14,21]}$ cranial subluxation still occurred in most cases. ${ }^{[21]}$ Inverse (=reverse) shoulder prosthesis implantation is performed only with the abductor function of $\mathrm{M}$. Deltoideus in patients where all rotator cuff muscles are resected..$^{[16,24-32]}$ The convex glenoidal component is connected to the concave humeral component in this prosthetic model. This arrangement of the parts forming the joint only depends on the stability of the glenohumeral rotation center. Relatively positive results were achieved in the long term with this prosthetic model..$^{[4-6,16,24-28]}$ Treatment of shoulder joint arthrosis with a large rotator cuff defect using an inverse shoulder prosthesis was found to be superior to other methods. ${ }^{[28,30]} \mathrm{A}$ significant increase was found in the thoracoscapular joint movement and the deltoid abduction muscle strength increased to almost twice on clinical follow-up and three-dimensional CT of these patients. The full defect or resection of the rotator cuff was present in all the patients included in this study. ${ }^{[24-30]}$ Another group reported that a large glenoid defect and deltoid muscle or axillary nerve defects were contraindications while a patient age over 65 was a relative contraindication for inverse prosthesis procedures. ${ }^{[24]}$ Latissimus dorsi transfer was performed in a study on patients with an intraoperative rotator cuff defect. It has been demonstrated that postoperative good shoulder function is possible with this surgical technique. Cranial subluxation in the implanted shoulder prosthesis was prevented with the transfer of $M$. latissimus dorsi. ${ }^{[33]}$ Treatments with the new methods mentioned above are continuing and detailed clinical results are expected in the long term. Another complication may be the infection of the soft tissue cover over the prosthesis. The prosthesis was removed totally because it was infected and risk of soft tissue perforation developed in one of our cases and implantation was avoided by placing septopalket. Despite the limitation of the postoperative movement, the majority of the patients could perform chores on their own and meet their needs. The main symptom was mild pain in many patients and severe pain in some others. We observed that some patients had no pain at all. The mean value in MSTS Scoring was found to be $63.7 \%$ during the follow-up in our study. This value was reported as $70.4 \%-85 \%$ (mean $77.6 \%$ ) in similar studies. ${ }^{[10,14,21,22]}$ All patients could fully perform elbow, forearm and hand functions during the postoperative period and were very satisfied. The patients were found to be satisfied despite a limitation and decrease in shoulder joint functions in other studies, similar to our study. ${ }^{[14,19]}$ 
Significant strength loss occurred in many patients postoperatively. However, there was no need to strengthen the muscles postoperatively if large muscle tissue was not resected during surgery and all movements could be performed to the same extent as before the surgery. Another problem is intraoperative muscle refixation. The refixation of the muscles to the prosthesis were made either on the already designed areas on the prosthesis, ${ }^{[7,17]}$ on the mesh graft ${ }^{[1,5,10,11,13-15,21,22]}$ or on the fascia lata band. ${ }^{[13,33]}$ However, despite such refixation, it was not possible to prevent subluxation of the head part of the shoulder prosthesis cranially due to the lack of or an inadequate pulling force. $M$. latissimus dorsi normally pulls the shoulder caudally but cannot provide sufficient force towards the cranium against the gravitational forces. The long head of the biceps tendon also has a depressive effect, but it was resected during tumor resection in almost all cases. When the depressive effect was thus eliminated, the movement of the prosthesis towards the cranium increased. After our follow-up, it was found that good movement capacity and muscle strength, although limited, could be achieved with the implantation of a modular tumor resection endoprosthesis following the resection of the primary and metastatic tumors of the proximal humerus despite intraoperative muscle and tendon refixation and some pain in the early period that could be tolerated when compared to the other treatment options such as arthrodesis or amputation. It is encouraging that the elbow, forearm and hand functions were fully protected in all patients and a satisfactory standard of quality of life was achieved, considering the cosmetic result, patient psychology and daily social activities.

Pre-, intra- and postoperative images of our cases in Group A and Group B have been presented in the following figures with explanations Figure. ${ }^{[1-11]}$

\section{Disclosures}

Peer-review: Externally peer-reviewed.

Conflict of Interest: None declared.

Ethics Committee Approval: The study was approved by the Local Ethics Committee.

Authorship Contributions: Concept - E.A.; Design - E.A.; Supervision - E.A.; Materials - E.A.; Data collection \&/or processing E.A.; Analysis and/or interpretation - E.A.; Literature search - E.A.; Writing - E.A.; Critical review - Y.Y.

\section{REFERENCES}

1. Frassica FJ, Sim FH, Chao EY. Primary malignant bone tumors of the shoulder girdle: surgical technique of resection and reconstruction. Am Surg 1987;53(5):264-9.

2. Donati D, Giacomini S, Gozzi E, Salphale Y, Mercuri M, Mankin
$\mathrm{HJ}$, et al. Allograft arthrodesis treatment of bone tumors: a two-center study. Clin Orthop Relat Res 2002;(400):217-24.

3. Gebhardt MC, Roth YF, Mankin HJ. Ostoearticular allografts for reconstruction in the proximal part of the humerus after excision of a musculoskeletal tumor. J Bone Joint Surg Am 1990;72(3):334-45. [CrossRef]

4. De Wilde L, Mombert M, Van Petegem P, Verdonk R. De Wilde L, Mombert M, Van Petegem P, Verdonk R. Acta Orthop Belg 2001;67(4):348-53.

5. Yalniz E, Ciftdemir M, Memişoğlu S. Functional results of patients treated with modular prosthetic replacement for bone tumors of the extremities. Acta Orthop Traumatol Turc 2008;42(4):238-45. [CrossRef]

6. Guven MF, Aslan L, Botanlioglu H, Kaynak G, Kesmezacar H, Babacan M. Functional outcome of reverse shoulder tumor prosthesis in the treatment of proximal humerus tumors. J Shoulder Elbow Surg 2016;25(1):e1-6. [CrossRef]

7. Gouin F, Creen V. Reconstruction following shoulder resection for bone tumor. Bull Cancer 2014;101(10):951-7. [CrossRef]

8. Constant CR, Murley AH. A clinical method of functional assessment of the shoulder. Clin Orthop Relat Res 1987;(214):160-4.

9. Enneking WF, Dunham W, Gebhardt MC, Malawar M, Pritchard DJ. A system for the functional evaluation of reconstructive procedures after surgical treatment of tumors of the musculoskeletal system. Clin Orthop Relat Res 1993;(286):241-6.

10. Asavamongkolkul A, Eckardt JJ, Eilber FR, Dorey FJ, Ward WG, Kelly CM, et al. Endoprosthetic reconstruction for malignant upper extremity tumors. Clin Orthop Relat Res 1999;(360):207-20. [CrossRef]

11. Fuhrmann RA, Roth $A$, Venbrocks RA. Salvage of the upper extremity in cases of tumorous destruction of the proximal humerus. J Cancer Res Clin Oncol 2000;126(6):337-44. [CrossRef]

12. Lee SH, Kim DJ, Oh JH, Han HS, Yoo KH, Kim HS. Validation of a functional evaluation system in patients with musculoskeletal tumors. Clin Orthop Relat Res 2003;(411):217-26. [CrossRef]

13. Sperling JW, Cofield RH, Rowland CM. Neer hemiarthroplasty and Neer total shoulder arthroplasty in patients fifty years old or less. Long-term results. J Bone Joint Surg Am 1998;80(4):464-73. [CrossRef]

14. Kumar D, Grimer RJ, Abudu A, Carter SR, Tillman RM. Endoprosthetic replacement of the proximal humerus. Long-term results. J Bone Joint Surg Br 2003;85(5):717-22. [CrossRef]

15. Kassab M, Dumaine V, Babinet A, Ouaknine M, Tomeno B, Anract $P$. Twenty nine shoulder reconstructions after resection of the proximal humerus for neoplasm with mean 7-year followup. Rev Chir Orthop Reparatrice Appar Mot 2005;91(1):15-23.

16. De Wilde LF, Van Ovost E, Uyttendaele D, Verdonk R. Results of an inverted shoulder prosthesis after resection for tumor of the proximal humerus. Chir Orthop Reparatrice Appar Mot 2002;88(4):373-8.

17. Huckstep RL, Sherry E. Replacement of the proximal humerus 
in primary bone tumours. Aust N Z J Surg 1996;66(2):97-100.

18. Shin KH, Park HJ, Yoo JH, Hahn SB. Reconstructive surgery in primary malignant and aggressive benign bone tumor of the proximal humerus. Yonsei Med J 2000;41(3):304-11. [CrossRef]

19. Boileau P, Walch G, Noël E, Liotard JP. Neer's shoulder prosthesis: results according to etiology. Rev Rhum Ed Fr 1994;61(9):607-18.

20. Damron TA, Rock MG, O'Connor MI, Johnson M, An KN, Pritchard DJ, et al. Functional laboratory assessment after oncologic shoulder joint resections. Clin Orthop Relat Res 1998;(348):124-34. [CrossRef]

21. Gosheger G, Hillmann A, Lindner N, Rödl R, Hoffmann C, Bürger $\mathrm{H}$, et al. Soft Tissue Reconstruction of Megaprostheses Using Trevira Tube. Clin Orthop Relat Res 2001;(393):264-71.

22. Wittig JC, Bickels J, Kellar-Graney KL, Kim FH, Malawer MM. Osteosarcoma of the proximal humerus: long-term results with limb-sparing surgery. Clin Orthop Relat Res 2002;(397):15676. [CrossRef]

23. Movin T, Sjoden GO, Ahrengart L. Poor function after shoulder replacement in fracture patients. A retrospective evaluation of 29 patients followed for 2-12 years. Acta Orthop Scand 1998;69(4):392-6. [CrossRef]

24. Seebauer L, Walter W, Keyl W. Reverse total shoulder arthroplasty for the treatment of defect arthropathy. Oper Orthop Traumatol 2005;17(1):1-24. [CrossRef]

25. De Wilde LF, Plasschaert FS. Audenaert EA, Verdonk RC. Functional recovery after a reverse prosthesis for reconstruction of the proximal humerus in tumor surgery. Clin Orthop Relat Res 2005;430:156-62. [CrossRef]

26. Frankle M, Levy JC, Pupello D, Siegal S, Saleem A, Mighell M, et al. The reverse shoulder prosthesis for glenohumeral arthritis associated with severe rotator cuff deficiency. a minimum two-year follow-up study of sixty patients surgical technique. J Bone Joint Surg Am 2006;88:178-90. [CrossRef]

27. Guery J, Favard L, Sirveaux F, Oudet D, Mole D, Walch G. Reverse total shoulder arthroplasty. Survivorship analysis of eighty replacements followed for five to ten years. J Bone Joint Surg Am 2006;88(8):1742-7. [CrossRef]

28. Gutiérrez S, Greiwe RM, Frankle MA, Siegal S, Lee WE 3rd. Biomechanical comparison of component position and hardware failure in the reverse shoulder prosthesis. J Shoulder Elbow Surg 2007;16(3):S9-S12. [CrossRef]

29. Zumstein M, Helmy N, Gerber C, Jost B. Schulterprothetik und sport. Schweizerische Zeitschrift für Sportmedizin und sporttraumatologie. Schweizerische: Gesellschaft für Sportmedizin SGSM; 2006. p. 6-12.

30. Levy JC, Virani N, Pupello D, Frankle M. Use of the reverse shoulder prosthesis for the Treatment of failed hemiarthroplasty in patients with glenohumeral arthritis and rotator cuff deficiency. J Bone Joint Surg Br 2007;8(2):189-95. [CrossRef]

31. Habermeyer P, Ebert T. Aktueller Entwicklungsstand und Perspektiven der Schulterendoprothetik. Unfallchirurg 1999;102(9):667-68. [CrossRef]

32. Hedtmann A, Heers G. Principles of shoulder prosthesis implantation. Orthopade 2001;30(6):354-62. [CrossRef]

33. Irlenbusch U, Bensdorf M, Gansen HK, Lorenz U. Latissimus dorsi transfer in case of irreparable rotator cuff tear--a comparative analysis of primary and failed rotator cuff surgery, in dependence of deficiency grade and additional lesions. Z Orthop Ihre Grenzgeb 2003;141(6):650-6. [CrossRef] 